\title{
Mechanochemistry-assisted synthesis of hierarchical porous carbons applied as supercapacitors
}

\author{
Desirée Leistenschneider ${ }^{1}$, Nicolas Jäckel ${ }^{2,3}$, Felix Hippauf ${ }^{4}$, Volker Presser ${ }^{2,3}$ \\ and Lars Borchardt ${ }^{*} 1, \S$
}

\author{
Full Research Paper \\ Address: \\ ${ }^{1}$ Institute of Inorganic Chemistry, Technische Universität Dresden, \\ Dresden, Germany, ${ }^{2}$ INM - Leibniz Institute for New Materials \& \\ Saarland University, Saarbrücken, Germany, ${ }^{3}$ Department of \\ Materials Science and Engineering, Saarland University, \\ Saarbrücken, Germany and ${ }^{4}$ Fraunhofer Institute for Material and \\ Beam Technology IWS, Dresden, Germany

\section{Email:} \\ Lars Borchardt ${ }^{*}$ - lars.borchardt@tu-dresden.de \\ * Corresponding author \\ $\S$ Tel: +4935146334960 \\ Keywords: \\ electrochemical energy storage; mesoporous; microporous; \\ solvent-free; supercapacitor; templated carbon
}

Beilstein J. Org. Chem. 2017, 13, 1332-1341. doi:10.3762/bjoc. 13.130

Received: 16 March 2017

Accepted: 22 June 2017

Published: 06 July 2017

This article is part of the Thematic Series "Mechanochemistry".

Guest Editor: J. G. Hernández

(C) 2017 Leistenschneider et al.; licensee Beilstein-Institut. License and terms: see end of document.

\begin{abstract}
A solvent-free synthesis of hierarchical porous carbons is conducted by a facile and fast mechanochemical reaction in a ball mill. By means of a mechanochemical ball-milling approach, we obtained titanium(IV) citrate-based polymers, which have been processed via high temperature chlorine treatment to hierarchical porous carbons with a high specific surface area of up to $1814 \mathrm{~m}^{2} \mathrm{~g}^{-1}$ and well-defined pore structures. The carbons are applied as electrode materials in electric double-layer capacitors showing high specific capacitances with $98 \mathrm{~F} \mathrm{~g}^{-1}$ in organic and $138 \mathrm{~F} \mathrm{~g}^{-1}$ in an ionic liquid electrolyte as well as good rate capabilities, maintaining $87 \%$ of the initial capacitance with $1 \mathrm{M}$ TEA-BF 4 in acetonitrile $(\mathrm{ACN})$ and $81 \%$ at $10 \mathrm{~A} \mathrm{~g}^{-1}$ in EMIM-BF 4 .
\end{abstract}

\section{Introduction}

Porous carbons are key components in many energy and environmentally-relevant applications, such as catalysis [1], gas storage and separation [2,3], and electrochemical energy storage [4-6]. Among them, activated carbons derived from natural precursors such as coconut shells are widely used in industrial applications [7]. Due to their high specific surface area, predominantly provided by micropores, they can physisorb large quanti- ties of molecules. They are also particularly suitable as electrode materials for supercapacitors, in which the energy storage is based on the electrosorption of electrolyte ions on the electrode surface [8-10]. These micropores are usually introduced by physical or chemical activation, often leading to broad poresize distributions and non-uniform pore structures [11]. However, for size-selective applications [12], non-uniform broad pore- 
size distributions lead to lower performance metrics [13,14]; they are also detrimental to derive clear statements about structure-performance relationships for fundamental research, such as the influence of the pore size and the pore structure on (electro)sorption in energy storage devices [15-17]. Moreover, purely microporous carbons suffer from diffusion limitations resulting in low electrochemical performances at high charge/discharge rates $[4,18,19]$. Larger pores, like mesopores, or hierarchical micro-meso-macroporous pore systems, facilitate fast ion transport through the carbon pore network [20,21]. Therefore, synthesis approaches leading to such pore systems are highly desirable to improve the electrochemical performance of carbon supercapacitors.

A well-established strategy for designing the porosity of carbon materials involves hard or soft templates [22-24]. Hardtemplating utilizes metal oxide nanoparticles [25] and salts [26-28], which have to be synthesized in advance. Softtemplating employs surfactants or other structure-directing molecules, which self-assemble to form the desired template $[29,30]$. A severe disadvantage of both routes is the need of large amounts of solvents, eventually accumulating as waste during the process. Moreover, these approaches require multiple synthesis steps, including template synthesis, calcination, impregnation, pyrolysis, and template removal. Therefore, the preparation of porous carbons with a tailored pore structure by conventional templating processes is often time and cost-intensive and environmentally unfavorable. For a more sustainable carbon production, especially in industrial scale, it is necessary to reduce the number of synthesis steps and to minimize waste accumulation, at best by avoiding any solvents $[7,31]$.
Lately, mechanochemistry has gained momentum in organic chemistry [32-34]. The initiation of chemical reactions by mechanical forces enables organic and inorganic syntheses without the use of any solvent within short reaction times of only few minutes [32,35]. A mechanochemical synthesis also enables high yields, making it a promising approach to obtain carbons and carbon precursors [36,37]. So far, mechanochemical reactions for the synthesis of porous carbon materials have rarely been used [38]. For example, the preparation of nanocarbon structures such as graphene sheets or fullerenes [39-41] as well as porous carbonaceous polymers $[42,43]$ have been conducted mechanochemically. Our work demonstrates that a templating approach can be transferred into the solventfree environment of a ball mill, and thus simplify the synthesis of hierarchical porous carbons drastically. Moreover, it is the first proof that even well-defined carbon pore structures can be derived making use of solid-state conditions like ball-milling. In detail, we apply the Pechini method, an approach commonly used for the synthesis of uniform metal oxide nanoparticles to synthesize a titanium(IV) citrate-based polymer [44,45]. The Pechini method is applicable to synthesize templated mesoporous carbons [46-49], but has never been utilized for a solvent-free and rapid process based on mechanochemistry.

The combination of this approach with a high temperature chlorine treatment enabled us to simultaneously carbonize the polymer and selectively remove the titania. By this way, we obtained a hierarchical carbon with a high pore volume, high specific surface area, tunable mesopore volume, and a well-defined pore-size distribution. The material was further investigated as supercapacitor electrode using organic and ionic liquid electrolytes (Figure 1).

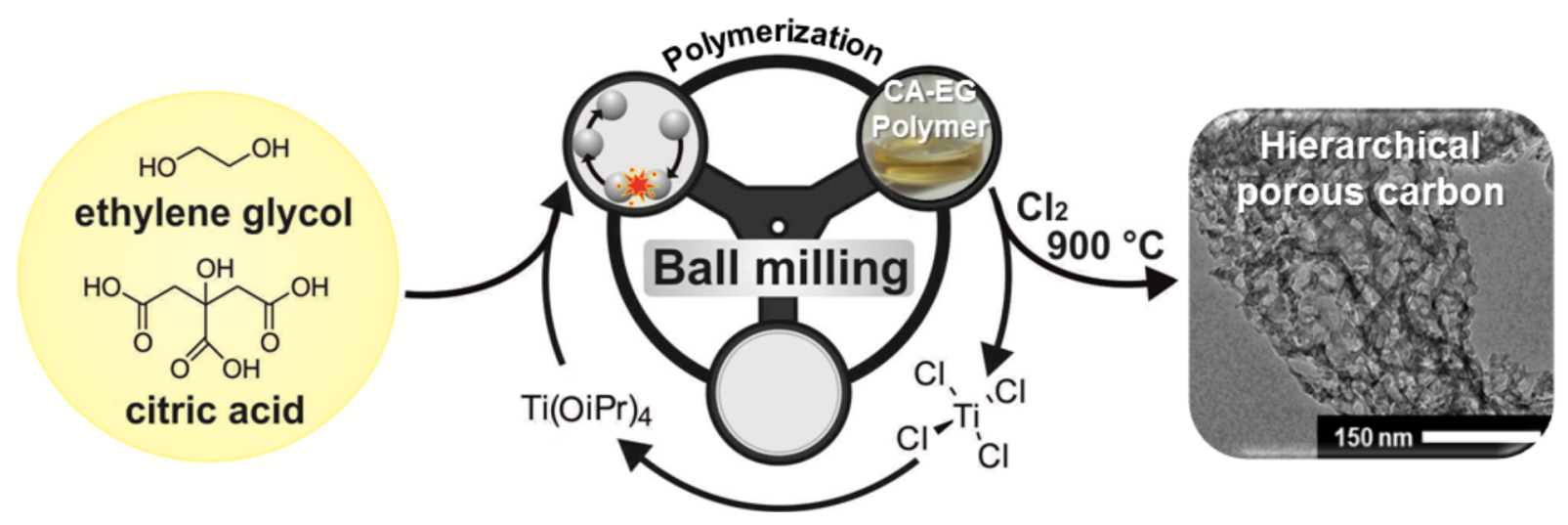

Figure 1: Synthesis of hierarchical porous carbons by mechanochemical polymerization of ethylene glycol (EG) with citric acid (CA) and Ti(IV) isopropoxide as a porogen, resulting in CA-EG polymers. After carbochlorination at $900{ }^{\circ} \mathrm{C}$ hierarchical carbons are obtained. The byproduct TiCl ${ }_{4}$ can be recycled to be used as Ti(IV) isopropoxide, and acts as porogen in further syntheses. 


\section{Results and Discussion}

\section{Mechanochemical synthesis of the polymeric precursor}

For a typical synthesis, ethylene glycol (EG), citric acid (CA), and titanium isopropoxide (TIPP) were ground with a molar ratio of 3:1:1 in a $\mathrm{ZrO}_{2}$ milling cup for $5 \mathrm{~min}$. A practical indicator for a successful mechanochemical reaction is a color change. The white and colorless educts turn to a yellow polymer with a honey-like texture. We first characterized the polymerization of the educts induced by mechanochemical forces by IR spectroscopy (Figure 2). Two bands at $1703 \mathrm{~cm}^{-1}$ and $1136 \mathrm{~cm}^{-1}$ appear, indicating the formation of the polyester (EG-CA). Likewise, the characteristic bands of the educts (CA: $1210 \mathrm{~cm}^{-1}$; EG: $1418 \mathrm{~cm}^{-1}$ ) become less pronounced and much broader as they are gradually consumed by the mechanically-induced polymerization. The spectrum of the Ti-containing polymer (Polymer-SF-3) displays the appearance of a band at $1558 \mathrm{~cm}^{-1}$, which corresponds to titanium, bidentate to a carboxylic group [50]. Additionally, the blue-shift of the vibration at $1703 \mathrm{~cm}^{-1}$ indicates complexation [51]. The sample Polymer-SF-3 was investigated by matrix-assisted laser desorption/ionization with a time-of-flight mass spectrometer (MALDI-TOF) revealing a weight-averaged molar mass $\left(M_{\mathrm{w}}\right)$ of $2015.6 \mathrm{~g} \mathrm{~mol}^{-1}$, which is equivalent to 6 monomeric units.

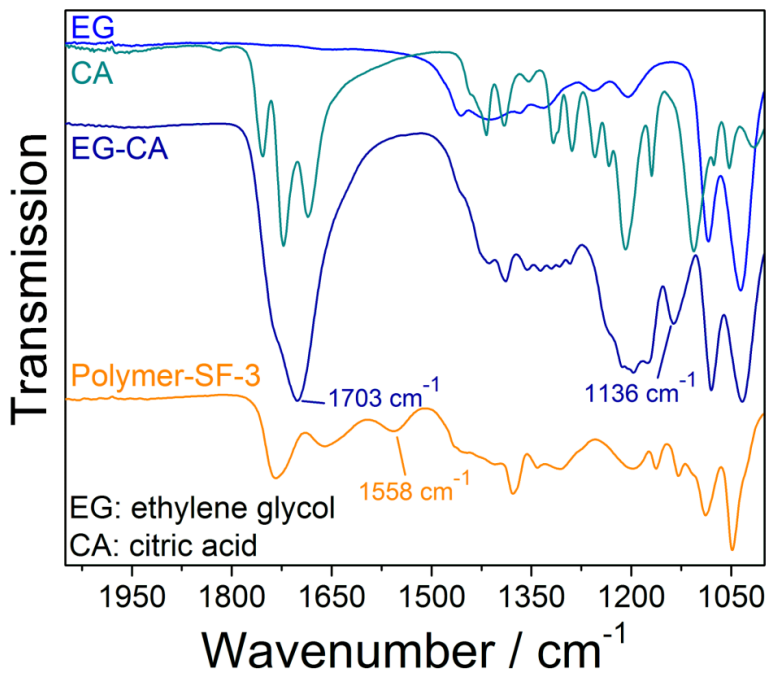

Figure 2: Infrared spectra of the monomers ethylene glycol (EG, blue) and citric acid (CA, green blue), the metal-free polymer achieved by 5 min ball milling with $\mathrm{ZrO}_{2}$ balls $(d=15 \mathrm{~mm})(\mathrm{EG}-\mathrm{CA}$, dark blue) and the polymeric precursor after adding titanium(IV) isopropoxide (Polymer-SF-3, orange)

\section{Synthesis of the hierarchical porous carbons}

After the mechanochemical synthesis, we conducted a carbochlorination reaction, leading to the carbonization of the precursor and the removal of the dispersed titanium species
(Equation 1). This process is comparable to the industrial Kroll process and responsible for the generation of mesopores that correspond to the size of the former titania nanostructures [25]. While titanium is removed as gaseous $\mathrm{TiCl}_{4}$, oxygen is extracted as $\mathrm{CO}$, whereby carbon is being partially consumed as well. This partial carbon removal leads to an etching of the carbon framework and an in situ formation of micropores, surrounding the formed mesopores. Consequently, a hierarchical porous carbon material is formed [52]. The resulting byproduct $\mathrm{TiCl}_{4}$ is a valuable precursor for Ti-containing [53] chemicals like Ti(IV) isopropoxide, other Ti-alkoxides, or can directly be applied in the presented synthesis approach once again [52].

$$
\mathrm{TiO}_{2}+(2+x) \mathrm{C}+2 \mathrm{Cl}_{2} \rightarrow \mathrm{TiCl}_{4}+2 \mathrm{CO}+x \mathrm{C}
$$

Scanning and transmission electron micrographs indicate that the carbon material exhibits spherically shaped mesopores (Figure 3), corresponding to the removal of $\mathrm{TiO}_{2}$ particles which have been formed during the pyrolysis (Figure 4). The pores are homogenously distributed, resulting in a wellconnected pore system of the carbon material (Figure 3A,B).

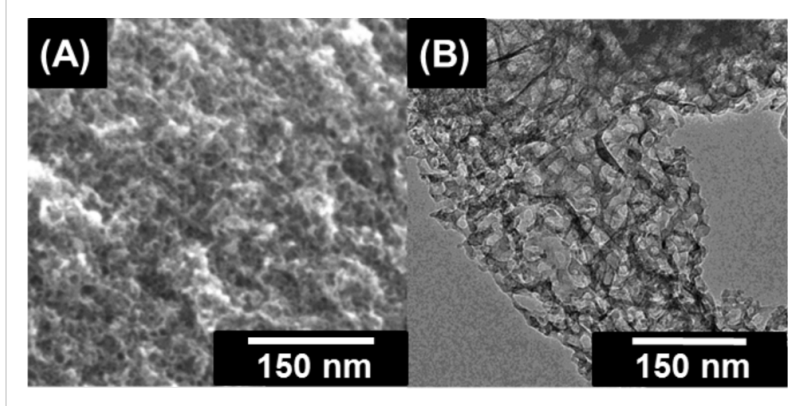

Figure 3: SEM (A) and TEM (B) images of the Carb-SF-3 sample.

To display the complete removal of the porogenous $\mathrm{TiO}_{2}$, we compared the XRD pattern (Figure 4) of the material at different synthesis steps: after mechanochemical polymerization (Polymer-SF-3), after temperature treatment but before $\mathrm{Cl}_{2}$ addition (Comp-SF-3), and after the carbochlorination reaction (Carb-SF-3).

The absence of X-ray reflections confirms the amorphous nature of the polymeric precursor. Titanium is atomically coordinated and distributed within the polymer and does not form crystalline $\mathrm{TiO}_{2}$ nanoparticle domains. After carbonization broadened reflections occur due to the conversion of the bidenated $\mathrm{Ti}$ atoms to $\mathrm{TiO}_{2}$ nanoparticles of the rutile and anatase modification. We calculated the average domain size of crystalline $\mathrm{TiO}_{2}$ from the reflections at $25.4^{\circ}, 48.0^{\circ}$, and $54.5^{\circ} 2 \theta$ to be $6-9 \mathrm{~nm}$ after background adjustment using the Scherrer equation. Carbochlorination will remove these nanoparticles, 


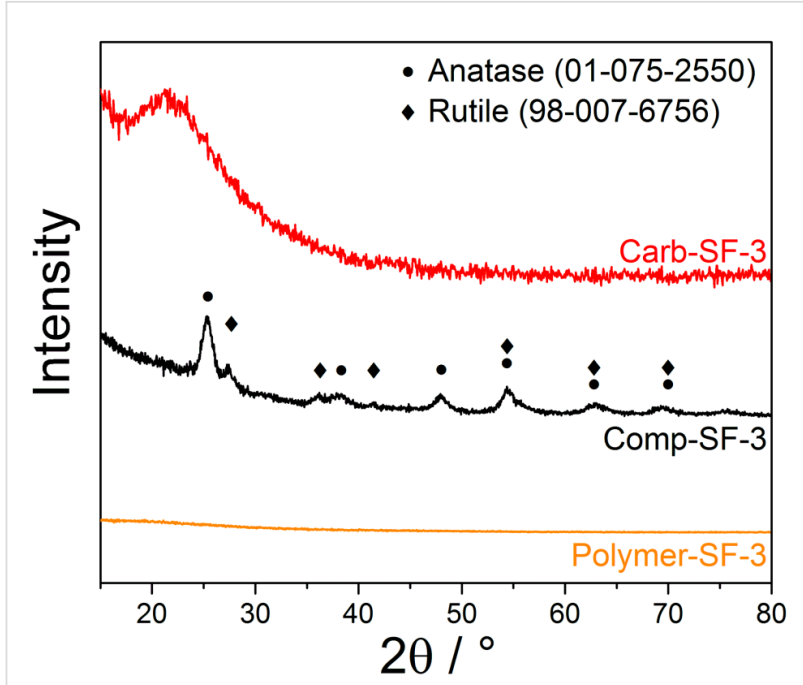

Figure 4: XRD-pattern of the polymeric precursor (Polymer-SF-3, orange), the carbonized composite (Comp-SF-3, black) and the carbon received by chlorine treatment (Carb-SF-3, red).

leading to mesopores of comparable size. The XRD pattern of the carbon shows the broad (002) reflection of nanocrystalline carbon, but all signals related to titania have disappeared. This assumption was further supported by EDX measurements (Table 1), showing a Ti content below the detection limit.

The pore structure of the materials was analyzed by nitrogen physisorption (Figure 5A). Neither the polymer (Polymer-SF-3) nor the carbonized composite material (Comp-SF-3) show a significant porosity (Table 1). This was expected since the porogens have not been removed during this step in the synthesis.
The low specific surface area of $298 \mathrm{~m}^{2} \mathrm{~g}^{-1}$ for the composite arises from chemical activation processes of volatile functional groups such as carboxylic acids, which form micropores during pyrolysis.

After carbochlorination at $900{ }^{\circ} \mathrm{C}$, the obtained carbon (CarbSF-3) shows a well-developed micro- and mesoporosity, obvious due to a type IV isotherm and a high nitrogen uptake at low relative pressure, which is attributed to the amount of micropores in the samples. The obtained material has a high specific surface area of up to $1814 \mathrm{~m}^{2} \mathrm{~g}^{-1}$ and a pore volume of $1.83 \mathrm{~cm}^{3} \mathrm{~g}^{-1}$. The contributions of the individual pore-size increments are shown in Table 1 and Figure 6 . The carbons possess narrowly distributed micropores with an average size of $0.96 \mathrm{~nm}$ (due to the in situ activation process), as well as mesopores with an average diameter of $8 \mathrm{~nm}$ (due to the removal of $\mathrm{TiO}_{2}$ nanodomains) (Figure 6, Equation 1). The mesopore diameter (Table 1 and Figure 6) aligns very well with the calculated domain size of $\mathrm{TiO}_{2}$ nanocrystals derived from the Scherrer equation. A more precisely evaluation of the hierarchical pore structure is given in Table S1 in Supporting Information File 1.

We further investigated the influence of the EG to CA ratio on the porosity of the material, while keeping the TIPP to CA ratio constant (1:1). The pore volume increased with a higher content of ethylene glycol from $1.34 \mathrm{~cm}^{3} \mathrm{~g}^{-1}$ for a ratio of $1: 1$ to $1.83 \mathrm{~cm}^{3} \mathrm{~g}^{-1}$ for a ratio of $3: 1$. This is mainly attributed to the increased mesopore volume, while the micropore volume stayed nearly the same $\left(0.20 \mathrm{~cm}^{3} \mathrm{~g}^{-1}\right.$, Table 1$)$. The higher mesopore content originates from the higher amount of ethylene glycol,

\begin{tabular}{|c|c|c|c|c|c|c|c|}
\hline Samples ${ }^{a}$ & $\begin{array}{l}\mathrm{SSA}_{\mathrm{BET}}^{\mathrm{b}} \\
/ \mathrm{m}^{2} \mathrm{~g}^{-1}\end{array}$ & $\begin{array}{c}\mathrm{SSA}_{\mathrm{DFT}} \text {,microc } \\
/ \mathrm{m}^{2} \mathrm{~g}^{-1}\end{array}$ & $\begin{array}{c}V_{\text {total }}{ }^{\mathrm{d}} \\
/ \mathrm{cm}^{3} \mathrm{~g}^{-1}\end{array}$ & $\begin{array}{l}V_{\text {meso }}{ }^{\mathrm{e}} \\
/ \mathrm{cm}^{3} \mathrm{~g}^{-1}\end{array}$ & $\begin{array}{l}V_{\text {micro }}^{f} \\
/ \mathrm{cm}^{3} \mathrm{~g}^{-1}\end{array}$ & $\begin{array}{c}\mathrm{d}_{\text {mesopore }} \mathrm{g} \\
/ \mathrm{nm}\end{array}$ & $\operatorname{Ti}_{/ \%}$ \\
\hline Polymer-SF-3i & - & - & - & - & - & - & $15.7^{j}$ \\
\hline Comp-SF-3 & 298 & 185 & 0.17 & 0.10 & 0.07 & - & $45.8 \pm 13.4$ \\
\hline Carb-SF-1 & 1442 & 623 & 1.34 & 1.11 & 0.23 & $4-14$ & $<$ d.l. \\
\hline Carb-SF-2 & 1532 & 480 & 1.62 & 1.43 & 0.19 & $4 ; 6-12$ & $<$ d.l. \\
\hline Carb-SF-3 & 1814 & 558 & 1.83 & 1.62 & 0.23 & $4 ; 6-14$ & $<$ d.l. \\
\hline Carb $_{\mathrm{HF}}-\mathrm{SF}-3$ & 291 & 144 & 0.20 & 0.14 & 0.06 & - & n.d. \\
\hline Comp-LA-3 & 312 & 173 & 0.18 & 0.14 & 0.04 & - & $62.8 \pm 16.7$ \\
\hline Carb-LA-3 & 1590 & 445 & 1.59 & 1.41 & 0.18 & $4 ; 6-13$ & $<$ d.I. \\
\hline Carb $_{\mathrm{HF}}-\mathrm{LA}-3$ & 706 & 123 & 0.62 & 0.48 & 0.14 & $4-12$ & 11.1 \\
\hline
\end{tabular}

aSample code $x-y-z$ as follows, $x$ describes the material after polymerization (Polymer), after heat treatment (Comp) and after carbochlorination (Carbon), the indices HF notices that the template was removed by $\mathrm{HF}$ instead of $\mathrm{Cl}_{2}$, y describes the reaction conducted solvent-free (SF) or liquid-

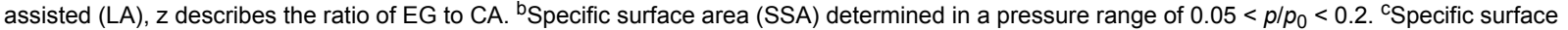
area of the mesopores determined by QSDFT below $2 \mathrm{~nm}$. ${ }^{\mathrm{d}}$ Total pore volume determined at $p / p_{0}=0.99$. ${ }^{\text {e Mesopore volume }}=V_{\text {total }}-V_{\text {micro }}$. ${ }_{\mathrm{f}}$ Micropore volume determined by QSDFT below $2 \mathrm{~nm}$. 9Mesopore size determined by QSDFT kernel for slit-shaped, cylindrical, spherical pores using the adsorption branch. ${ }^{\mathrm{h}} \mathrm{Ti}$ content determined by EDX measurement, < d.I. = below detection limit. ${ }^{\mathrm{i}}$ The polymer is non-porous. ${ }^{\mathrm{j}} \mathrm{The}$ polymer is not stable in the electron beam; therefore, the composition must be determined from thermogravimetric analysis (TG) rather than from EDX. 

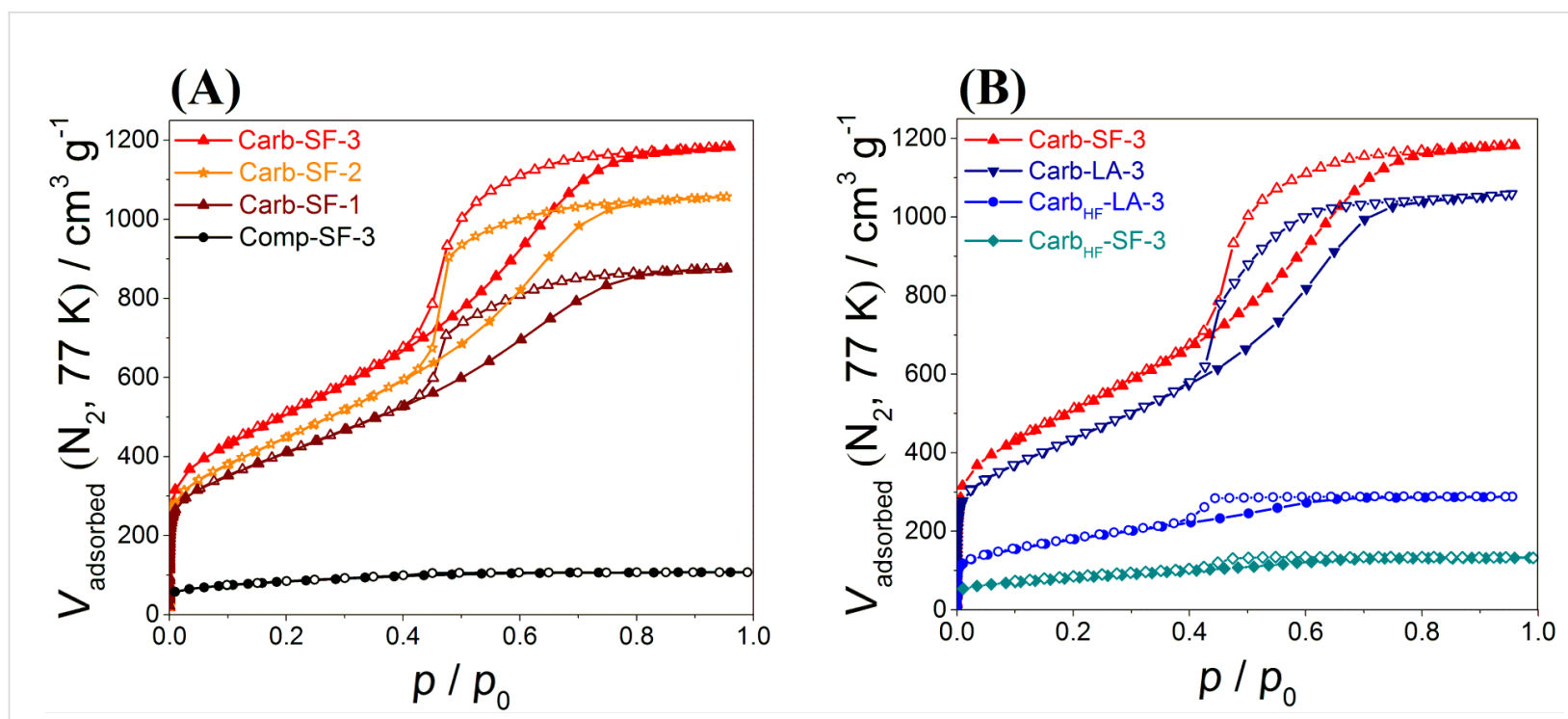

Figure 5: Nitrogen physisorption isotherms for carbon samples achieved from (A) different amounts of ethylene glycol and (B) different syntheses.

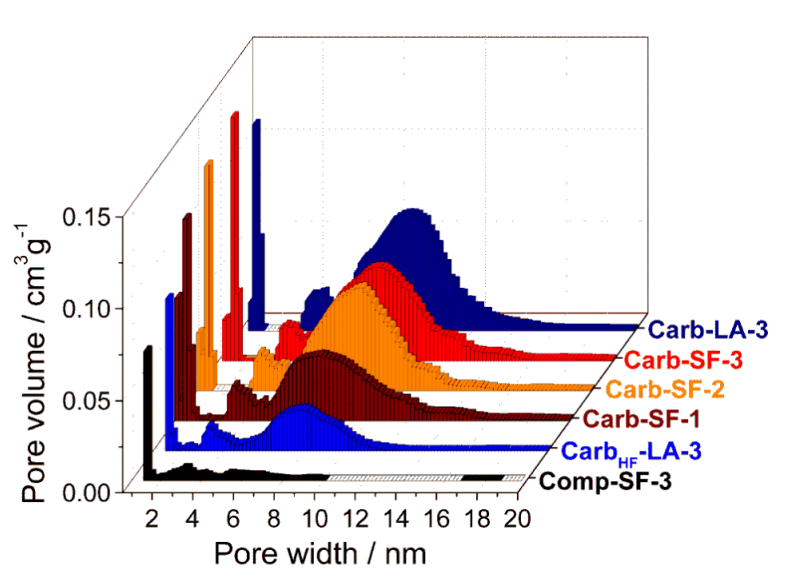

Figure 6: Volume histogram of the different samples calculated using a QSDFT-kernel for slit, cylindrical and spherical pores on the adsorption branch.

which promotes the formation of more slightly larger pores. This process finally leads to a higher mesopore volume at the expense of a narrower pore-size distribution (Figure 6). The EG ratio does not impact the particle size of the $\mathrm{TiO}_{2}$ nanostructures and thus the pore-size distributions are similar for all investigated materials (average diameter of $8 \mathrm{~nm}$ ). The reaction in total absence of EG yields white powder next to purely black carbon phases (see Figure S2, Supporting Information File 1) This indicates that the carbon content was insufficient and demonstrates the inevitable role of EG.

To further investigate the mechanochemical polymerization and the carbochlorination step, we conducted the synthesis under liquid-assisted conditions while adding ethanol as a solvent to see if there is a difference in the polymerization and investigated an alternative template removal approach based on etching with hydrofluoric acid (HF) as well [54]. The latter is a common process used in industry [55]. However, by doing so, it is impossible to remove the porogenous $\mathrm{TiO}_{2}$ completely from the carbon matrix (sample $\mathrm{Carb}_{\mathrm{HF}}-\mathrm{SF}-3$ ). The resulting material still contained $11.1 \mathrm{wt} \%$ of $\mathrm{Ti}$ and did not show a high porosity (Figure 5B and Table 1) with a pore volume of $0.20 \mathrm{~cm}^{3} \mathrm{~g}^{-1}$ and a surface area of $291 \mathrm{~m}^{2} \mathrm{~g}^{-1}$. Indeed, the high temperature chlorination reaction is essential to obtain the full porosity of the desired carbon. However, when we conducted the mechanochemical polymerization in the presence of small amounts of ethanol (liquid-assisted grinding, LA), the porogens

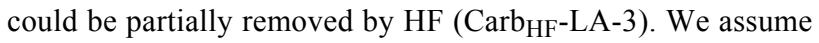
that the carbon matrix obtained from a solvent-free approach is possibly denser and thus the diffusion of HF to the particles is inhibited (incomplete removal). This aligns with the assumption that the energy-input and accordingly the embedding of the particles are higher in case of solvent-free syntheses. When we compare SF and LA samples (both received by carbochlorination), we observe full template removal and obtain hierarchical porous carbons with high surface area and pore volume (Table 1 and Figure 5B). The addition of a solvent during the mechanochemical synthesis does not influence the porosity of the composite materials, since both composites (Comp-SF-3 and Comp-LA-3) provide the same pore volume $\left(0.2 \mathrm{~cm}^{3} \mathrm{~g}^{-1}\right)$ and SSA (300 $\mathrm{m}^{2} \mathrm{~g}^{-1}$, Table 1). However, the carbons derived after carbochlorination differ in their porosities. The solventfree synthesis results in a higher specific surface area and pore volume as compared to the liquid-assisted approach. We 
suggest that this is also attributed to more homogenously distributed particles while conducting the polymerization solventfree. In the presence of solvents, a phase-separation phenomena might be induced, which results in a lower pore volume of the received carbon material (Table 1). Although chlorine gas is widely used in many industrial processes such as the Kroll process, it should be the attempt of future research to substitute chlorine gas by a green alternative to advance this mechanochemical process to an even more sustainable synthesis.

\section{Application as supercapacitor electrodes}

We selected Carb-SF-3 as electrode material in a symmetrical supercapacitor because of its high specific surface area and pore volume (Table 1). The electrochemical characterization was done in $1 \mathrm{M}$ TEA-BF 4 in acetonitrile $(\mathrm{ACN})$ and neat EMIM$\mathrm{BF}_{4}$ as an ionic liquid. Since ionic liquids show a lower ion mobility as compared to aqueous or organic electrolytes, a wellconnected transport pore system is of particular importance to guarantee a fast ion transport and should result in better power performance $[21,56]$. Hierarchical pore systems provide enhanced ion transport in meso-/macropores in combination with high energy density due to accessible surface area in micropores [21].

The energy storage is accomplished by ion electrosorption as can be inferred from the rectangular shaped cyclic voltammograms (CVs) in both electrolytes (Figure 7A,B) [53]. At low current rates, the material shows good specific capacitance (Table 2) of $138 \mathrm{~F} \mathrm{~g}^{-1}$ in neat EMIM-BF 4 and $98 \mathrm{~F} \mathrm{~g}^{-1}$ in $1 \mathrm{M}$ $\mathrm{TEA}^{-\mathrm{BF}_{4}}(\mathrm{ACN})$ determined by galvanostatic cycling with potential limitation at $0.1 \mathrm{~A} \mathrm{~g}^{-1}$. These values are comparable to other known Kroll carbons [52] and non-doped mesoporous carbons [57].
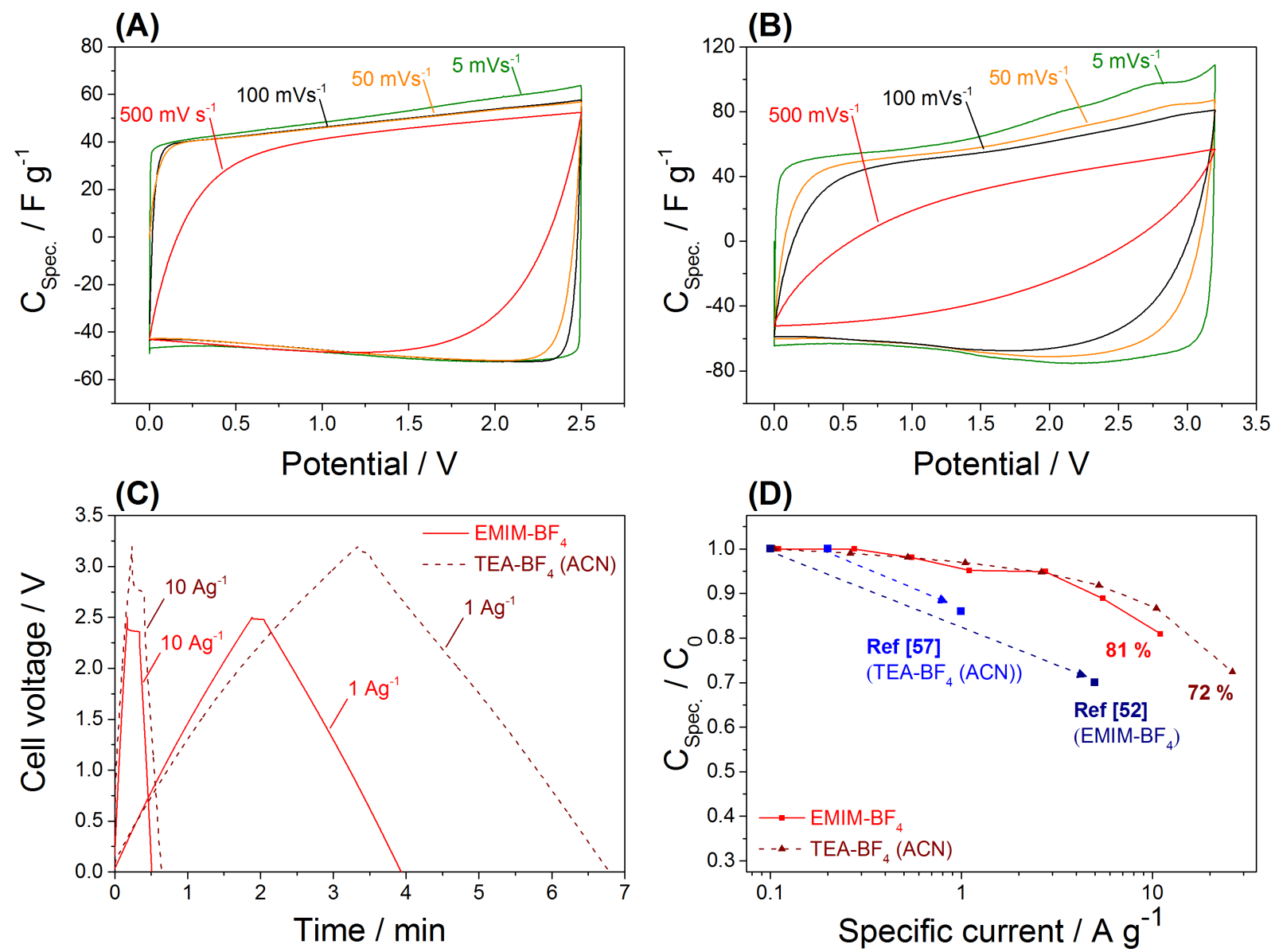

Figure 7: Cyclic voltammograms performed with different scan rates in $(A) 1 \mathrm{M}$ TEA-BF $4(A C N)$ and $(B) E^{2} I_{M-B F}$; galvanostatic charge/discharge curves in two different electrolytes at different specific currents (C); normalized rate capability test with different specific currents (D) in comparison to another Kroll carbon (from [52]) and a mesoporous template carbon (from [57]) with comparable mesopore sizes and surface areas. 
Table 2: Electrochemical data summary for sample Carb-SF-3 measured in two different electrolytes.

\begin{tabular}{|c|c|c|c|c|c|c|}
\hline Sample & Electrolyte $^{a}$ & $\begin{array}{c}\mathrm{C}_{0}^{\mathrm{b}} \\
/ \mathrm{F} \mathrm{g}^{-1}\end{array}$ & $\begin{array}{c}C_{0}{ }^{c} \\
/ \mathrm{F} \mathrm{m}^{-2}\end{array}$ & $\begin{array}{c}\text { Capacitance loss } \\
/ \%\end{array}$ & $\begin{array}{l}\text { Specific energy } \\
\quad / \mathrm{Wh} \mathrm{kg}^{-1}\end{array}$ & $\begin{array}{c}\text { Energy efficiency } \\
\qquad / \%\end{array}$ \\
\hline Carb-SF-3 & $\mathrm{O}$ & 98 & 0.054 & $13^{f}$ & 18.99 & 95.0 \\
\hline Carb-SF-3 & IL & 138 & 0.076 & $19^{f}$ & 41.30 & 83.5 \\
\hline $\operatorname{Ref}[52]^{g}$ & IL & 135 & 0.072 & $30^{f}$ & n. d. & n. d. \\
\hline $\operatorname{Ref}[57]^{\mathrm{h}}$ & $\mathrm{O}$ & 93 & 0.062 & $14^{i}$ & n. d. & n. d. \\
\hline
\end{tabular}

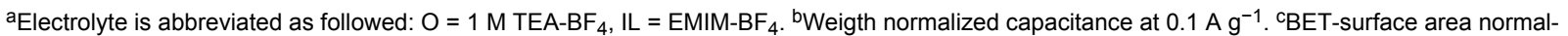
ized capacitance at $0.1 \mathrm{~A} \mathrm{~g}^{-1}$, d Specific energy obtained from discharge at $1 \mathrm{~A} \mathrm{~g}^{-1}$ measured in $1 \mathrm{M} \mathrm{TEA-BF}$ (ACN) and at $1 \mathrm{~A} \mathrm{~g}^{-1}$ in EMIM-BF 4 . eEnergy efficiency calculated as quotient of the specific energy obtained from discharge and charge at $1 \mathrm{~A} \mathrm{~g} \mathrm{~g}^{-1}$ loss of specific capacitance, calculated as 1 - quotient of $C_{\mathrm{spec}}$ at $1 \mathrm{~A} \mathrm{~g}^{-1}$ and $C_{0}$. ${ }^{\mathrm{f}}$ Loss of specific capacitance, calculated as $1-$ quotient of $C_{\text {spec }}$ at $10 \mathrm{~A} \mathrm{~g}{ }^{-1}$ and $C_{0}$. ${ }^{\text {gReference Kroll }}$ carbon. ${ }^{\mathrm{h}}$ Reference mesoporous carbon. 'Loss of specific capacitance, calculated as 1 - quotient of $C_{\mathrm{spec}}$ at $1 \mathrm{~A} \mathrm{~g}{ }^{-1}$ and $C_{0}$ reference non-doped mesoporous carbon.

At a high sweep rate of $500 \mathrm{mV} \mathrm{s}^{-1}$, the shape of the $\mathrm{CV}$, recorded in the organic electrolyte (Figure 7A) remains nearly rectangular, which indicated a high power handling ability. The ion mobility of ionic liquids is lower compared to organic electrolytes, as can be seen from the stronger deformation of the $\mathrm{CV}$ at high scan rates (Figure 7B). The different rate handling is also quantified by galvanostatic cycling with potential limitation (GCPL) conducted at different specific currents as presented in Figure 7C. At a high current rate of $10 \mathrm{~A} \mathrm{~g}^{-1}$, the specific capacitance was $87 \%$ in the organic electrolyte and

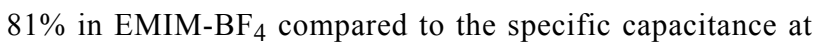
$0.1 \mathrm{~A} \mathrm{~g}^{-1}$. The ability of the carbon to enable a fast charge and discharge is superior compared to other mesoporous non-doped carbon electrodes (Figure 7D). The material also exhibited excellent performance stability, as seen from $92 \%$ and $95 \%$ after $100 \mathrm{~h}$ of floating at $2.7 \mathrm{~V}$ for TEA-BF 4 in $\mathrm{ACN}$ and $3.2 \mathrm{~V}$

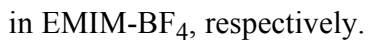

\section{Conclusion}

Our work presents a novel, solvent-free approach to receive hierarchical porous carbons with tailorable mesopore volume involving two synthesis steps: firstly, the mechanochemical synthesis of a polymeric composite, received by ball-milling within five minutes only, and secondly, the conversion of this precursor to a hierarchical carbon by a carbochlorination reaction. The received carbons exhibit specific surface areas of up to $1800 \mathrm{~m}^{2} \mathrm{~g}^{-1}$ and high mesopore volumes up to $1.8 \mathrm{~cm}^{3} \mathrm{~g}^{-1}$, making them very attractive for energy applications. When benchmarked as supercapacitor electrode material, Carb-SF-3 shows good specific capacitances with $98 \mathrm{~F} \mathrm{~g}^{-1}$ in $1 \mathrm{M}$ TEA$\mathrm{BF}_{4}(\mathrm{ACN})$ and $138 \mathrm{~F} \mathrm{~g}^{-1}$ in EMIM-BF 4 . Even with high specific currents of $10 \mathrm{~A} \mathrm{~g}^{-1}$ the carbon shows $87 \%$ in organic and $91 \%$ in ionic liquid electrolyte of its specific capacitance. Moreover, the carbon enables a stable electrochemical performance in both surveyed electrolytes with over $92 \%$ capacitance retention after $100 \mathrm{~h}$ of voltage floating. Due to the ability to design the mesopore volumes and their relatively narrow pore size distribution, the carbons are also interesting as model carbons for the investigation of different adsorption phenomena.

\section{Experimental Synthesis}

Citric acid monohydrate (CA, purity: 95.5\%) and titanium isopropoxide (TIPP, purity: 97\%) were purchased from SigmaAldrich. Ethylene glycol (EG, purity 99.5\%) was purchased from Fluka Analytics.

For the solvent-free synthesis of hierarchical porous carbons, $5.25 \mathrm{~g} \mathrm{CA}$ were ground with $7.10 \mathrm{~g}$ TIPP in a molar ratio of 1:1

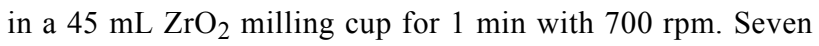
grinding balls out of $\mathrm{ZrO}_{2}$ with a diameter of $15 \mathrm{~mm}$ were used. Afterwards, different amounts of EG are added and the mixture was ball-milled for another $5 \mathrm{~min}$ with $700 \mathrm{rpm}$. The molar ratio of $\mathrm{CA}$ and $\mathrm{EG}$ was varied from $1: 3$ to $1: 1$. For the liquidassisted synthesis, $5 \mathrm{~mL}$ EtOH were added to the first grinding step.

The resulting polymer was heated to $900{ }^{\circ} \mathrm{C}$ at a heating rate of $300{ }^{\circ} \mathrm{C} \mathrm{h}^{-1}$ in a horizontal tubular furnace under argon atmosphere with a flowrate of $150 \mathrm{~mL} \mathrm{~min}^{-1}$. After $1 \mathrm{~h}$ at $900{ }^{\circ} \mathrm{C}$, the gas atmosphere was changed to a mixture of argon (flowrate: $70 \mathrm{~mL} \mathrm{~min}^{-1}$ ) and chlorine gas (flowrate: $80 \mathrm{~mL} \mathrm{~min}^{-1}$ ) while the temperature was held for additional $2 \mathrm{~h}$ at $900{ }^{\circ} \mathrm{C}$. After cooling to $600{ }^{\circ} \mathrm{C}$ under argon, remaining chlorine was removed by hydrogen treatment (flowrate: $80 \mathrm{~mL} \mathrm{~min}^{-1}$ ) for $1 \mathrm{~h}$.

\section{Characterization}

Nitrogen physisorption experiments were carried out with an AUTOSORB-iQ-C-XR from Quantachrome at $-196{ }^{\circ} \mathrm{C}$. Prior to the measurements, the samples were degassed for at least $24 \mathrm{~h}$ at $150{ }^{\circ} \mathrm{C}$ under vacuum. The specific surface area was 
calculated in a relative pressure range of $0.05-0.2$ per the Brunauer-Emmett-Teller (BET) theory. Values for the total pore volume were determined at a relative pressure of 0.99 . Pore size distributions were achieved by applying the hybrid QSDFT model for slit-shaped, cylindrical and spherical pores at $-196^{\circ} \mathrm{C}$. The micropore volume was calculated from the cumulative QSDFT pore volume data at $2 \mathrm{~nm}$. Energy dispersive $\mathrm{X}$-ray (EDX) analyses were performed with a SU8020 from Hitachi at an acceleration voltage of $20 \mathrm{kV}$. Transmission electron microscopy (TEM) was executed with a TEM Libra 200 system from Carl Zeiss Microscopy $\mathrm{GmbH}$ with an acceleration voltage of $200 \mathrm{kV}$. For the TEM, the sample powder was sonicated in acetone for $5 \mathrm{~s}$. A lacey-carbon film on copper net (300 mesh) from Plano was used as TEM grid. Afterward, $5 \mu \mathrm{L}$ were dropped on the grid and evaporated. IR spectra were conducted with the use of ATR technique, as well as with the DRIFTS technique with a Bruker Vertex 70 in the range of $4000-400 \mathrm{~cm}^{-1}$. The hierarchical porous carbon was prepared as free standing electrodes. The carbon material was dispersed in ethanol and we added $10 \mathrm{wt} \%$ polytetrafluoroethylene (PTFE, $60 \mathrm{wt} \%$ solution in water) as the polymer binder. By crushing the mixture in an agate mortar until the ethanol is evaporated, a dough-like mass was obtained, which was further rolled out until the electrode had a thickness of about $150 \mu \mathrm{m}$. The electrode was dried in a vacuum oven at $120{ }^{\circ} \mathrm{C}$ for $24 \mathrm{~h}$ and we used a disc cutter to obtain electrodes with a diameter of $12 \mathrm{~mm}$. The measurement was done in custom-built cells in a symmetrical two-electrode setup with a quasi-reference electrode out of YP-50F bound with PTFE [58,59]. A 13 mm diameter Whatmann GF/D was used as a separator and $12 \mathrm{~mm}$ diameter carbon-coated aluminum discs from MTI Corporation was used as a current collector.

The electrochemical measurements were performed with a Biologic VMP-300 potentiostat/galvanostat. The specific capacitances were calculated with Equation 2 from galvanostatic cycling with potential limitation (GCPL). To compare the electrodes with other materials, they were normalized to their active mass, which is equivalent to the carbon mass in the electrodes, as well as to their specific surface area obtained by the BET method. For the graphical representation of the cyclic voltammograms, the specific capacitances were calculated with Equation 3 .

$$
\begin{gathered}
C_{\text {spec. }}=\frac{4 Q(\text { discharge })}{U \cdot m} \\
C_{\text {spec. }}=\frac{I(t)}{\left(\frac{d U(t)}{d t}\right) m}
\end{gathered}
$$

For the calculation of the specific energy of the carbon electrodes in two different electrolytes, Equation 4 was applied with discharge data after the iR drop.

$$
E=\frac{I}{m} \int U d t
$$

\section{Supporting Information}

\section{Supporting Information File 1}

Additional data.

[http://www.beilstein-journals.org/bjoc/content/

supplementary/1860-5397-13-130-S1.pdf]

\section{Acknowledgements}

DL and LB gratefully acknowledge the Federal Ministry of Education and Research (Bundesministerium für Bildung und Forschung, BMBF) for support of the Mechanocarb project (award number 03SF0498). DL wants to thank Kristian Schneider for the TEM measurement and the Leibniz-Institut für Polymerforschung Dresden e.V. for access to the TEM as well as Sebastian Ehrling for the SEM/EDX measurements. NJ and VP thank Prof. Eduard Arzt (INM) for his continuing support and Aura Tolosa (INM) for discussions.

\section{References}

1. Rodríguez-reinoso, F. Carbon 1998, 36, 159-175. doi:10.1016/S0008-6223(97)00173-5

2. Suda, H.; Haraya, K. Chem. Commun. 1997, 93-94. doi:10.1039/a606385c

3. Suda, H.; Haraya, K. J. Phys. Chem. B 1997, 101, 3988-3994. doi:10.1021/jp963997u

4. Rose, M.; Korenblit, Y.; Kockrick, E.; Borchardt, L.; Oschatz, M.; Kaskel, S.; Yushin, G. Small 2011, 7, 1108-1117. doi:10.1002/smll.201001898

5. Simon, P.; Taberna, P.-L.; Béguin, F. Electrical Double-Layer Capacitors and Carbons for EDLCs. In Supercapacitors: Materials, Systems, and Applications; Béguin, F.; Frackowiak, E., Eds.; Wiley-VCH: Weinheim, 2013; pp 131-165.

6. Oschatz, M.; Boukhalfa, S.; Nickel, W.; Hofmann, J. P.; Fischer, C.; Yushin, G.; Kaskel, S. Carbon 2017, 113, 283-291. doi:10.1016/j.carbon.2016.11.050

7. Titirici, M.-M.; White, R. J.; Brun, N.; Budarin, V. L.; Su, D. S.; del Monte, F.; Clark, J. H.; MacLachlan, M. J. Chem. Soc. Rev. 2015, 44, 250-290. doi:10.1039/C4CS00232F

8. Simon, P.; Gogotsi, Y. Nat. Mater. 2008, 7, 845-854. doi:10.1038/nmat2297

9. Merlet, C.; Rotenberg, B.; Madden, P. A.; Taberna, P.-L.; Simon, P.; Gogotsi, Y.; Salanne, M. Nat. Mater. 2012, 11, 306-310. doi:10.1038/nmat3260

10. Piwek, J.; Platek, A.; Fic, K.; Frackowiak, E. Electrochim. Acta 2016, 215, 179-186. doi:10.1016/j.electacta.2016.08.061

11. Borchardt, L.; Oschatz, M.; Kaskel, S. Mater. Horiz. 2014, 1, 157-168. doi:10.1039/C3MH00112A 
12. Hippauf, F.; Lunow, D.; Huettner, C.; Nickel, W.; Borchardt, L.; Henle, T.; Kaskel, S. Carbon 2015, 87, 309-316. doi:10.1016/j.carbon.2015.02.023

13. Kyotani, T. Carbon 2000, 38, 269-286. doi:10.1016/S0008-6223(99)00142-6

14. Jäckel, N.; Simon, P.; Gogotsi, Y.; Presser, V. ACS Energy Lett. 2016, 1, 1262-1265. doi:10.1021/acsenergylett.6b00516

15. Borchardt, L.; Nickel, W.; Casco, M.; Senkovska, I.; Bon, V.; Wallacher, D.; Grimm, N.; Krause, S.; Silvestre-Albero, J. Phys. Chem. Chem. Phys. 2016, 18, 20607-20614. doi:10.1039/C6CP03993F

16. Oschatz, M.; Hoffmann, H. C.; Pallmann, J.; Schaber, J.; Borchardt, L.; Nickel, W.; Senkovska, I.; Rico-Francés, S.; Silvestre-Albero, J.; Kaskel, S.; Brunner, E. Chem. Mater. 2014, 26, 3280-3288. doi:10.1021/cm501102y

17. Oschatz, M.; Borchardt, L.; Hippauf, F.; Nickel, W.; Kaskel, S.; Brunner, E. Annu. Rep. NMR Spectrosc. 2016, 87, 237-318. doi:10.1016/bs.arnmr.2015.08.003

18. Péan, C.; Merlet, C.; Rotenberg, B.; Madden, P. A.; Taberna, P.-L.; Daffos, B.; Salanne, M.; Simon, P. ACS Nano 2014, 8, 1576-1583. doi:10.1021/nn4058243

19. Oschatz, M.; Kockrick, E.; Rose, M.; Borchardt, L.; Klein, N.; Senkovska, I.; Freudenberg, T.; Korenblit, Y.; Yushin, G.; Kaskel, S. Carbon 2010, 48, 3987-3992. doi:10.1016/j.carbon.2010.06.058

20. Fuertes, A. B.; Pico, F.; Rojo, J. M. J. Power Sources 2004, 133, 329-336. doi:10.1016/j.jpowsour.2004.02.013

21. Wang, D.-W.; Li, F.; Liu, M.; Lu, G. Q.; Cheng, H.-M. Angew. Chem., Int. Ed. 2007, 47, 373-376. doi:10.1002/anie.200702721

22. Meng, Y.; Gu, D.; Zhang, F.; Shi, Y.; Yang, H.; Li, Z.; Yu, C.; Tu, B.; Zhao, D. Angew. Chem., Int. Ed. 2005, 44, 7053-7059. doi:10.1002/anie.200501561

23. Ryoo, R.; Joo, S. H.; Jun, S. J. Phys. Chem. B 1999, 103, 7743-7746. doi:10.1021/jp991673a

24. Wang, Y.; Wang, F.; Chen, Y.; Li, B.; Zhang, C.; Cui, L.; Kang, S.; Li, X. Int. J. Electrochem. Sci. 2013, 8, 7868-7874.

25. Oschatz, M.; Thieme, S.; Borchardt, L.; Lohe, M. R.; Biemelt, T.; Brückner, J.; Althues, H.; Kaskel, S. Chem. Commun. 2013, 49, 5832-5834. doi:10.1039/c3cc42841a

26. Fechler, N.; Fellinger, T.-P.; Antonietti, M. Adv. Mater. 2013, 25, 75-79. doi:10.1002/adma.201203422

27. Yang, C.-M.; Weidenthaler, C.; Spliethoff, B.; Mayanna, M.; Schüth, F. Chem. Mater. 2005, 10, 355-358. doi:10.1021/cm049164v

28. Zhu, H.; Liu, Z.; Wang, Y.; Kong, D.; Yuan, X.; Xie, Z. Chem. Mater. 2008, 20, 1134-1139. doi:10.1021/cm071385o

29. Chuenchom, L.; Kraehnert, R.; Smarsly, B. M. Soft Matter 2012, 8, 10801-10812. doi:10.1039/c2sm07448f

30. Sakintuna, B.; Yürüm, Y. Ind. Eng. Chem. Res. 2005, 44, 2893-2902. doi:10.1021/ie049080w

31. Gawande, M. B.; Bonifácio, V. D. B.; Luque, R.; Branco, P. S.; Varma, R. S. ChemSusChem 2014, 7, 24-44. doi:10.1002/cssc.201300485

32. Tojo, T.; Zhang, Q.; Saito, F. J. Solid State Chem. 2006, 179, 433-437. doi:10.1016/j.jssc.2005.11.002

33. Stolle, A.; Szuppa, T.; Leonhardt, S. E. S.; Ondruschka, B. Chem. Soc. Rev. 2011, 40, 2317-2329. doi:10.1039/c0cs00195c
34. James, S. L.; Adams, C. J.; Bolm, C.; Braga, D.; Collier, P.; Friščić, T.; Grepioni, F.; Harris, K. D. M.; Hyett, G.; Jones, W.; Krebs, A.; Mack, J.; Maini, L.; Orpen, A. G.; Parkin, I. P.; Shearouse, W. C.; Steed, J. W.; Waddell, D. C. Chem. Soc. Rev. 2012, 41, 413-447. doi:10.1039/C1CS15171A

35. Jörres, M.; Aceña, J. L.; Soloshonok, V. A.; Bolm, C. ChemCatChem 2015, 7, 1265-1269. doi:10.1002/cctc.201500102

36. Wang, Y.-F.; Chen, R.-X.; Wang, K.; Zhang, B.-B.; Li, Z.-B.; Xu, D.-Q. Green Chem. 2012, 14, 893-895. doi:10.1039/c2gc16521j

37. Grätz, S.; Borchardt, L. RSC Adv. 2016, 6, 64799-64802. doi:10.1039/C6RA15677K

38. Schneidermann, C.; Jäckel, N.; Oswald, S.; Giebeler, L.; Presser, V.; Borchardt, L. ChemSusChem 2017, 10, 2416-2424. doi:10.1002/cssc.201700459

39. Wang, G.-W.; Komatsu, K.; Murata, Y.; Shiro, M. Nature 1997, 387, 583-586. doi:10.1038/42439

40. Kabbani, M. A.; Tiwary, C. S.; Autreto, P. A. S.; Brunetto, G.; Som, A.; Krishnadas, K. R.; Ozden, S.; Hackenberg, K. P.; Gong, Y.; Galvao, D. S.; Vajtai, R.; Kabbani, A. T.; Pradeep, T.; Ajayan, P. M. Nat. Commun. 2015, 6, No. 7291. doi:10.1038/ncomms8291

41. Kunitake, M.; Uemura, S.; Ito, O.; Fujiwara, K.; Murata, Y.; Komatsu, K. Angew. Chem., Int. Ed. 2002, 41, 969-972. doi:10.1002/1521-3773(20020315)41:6<969::AID-ANIE969>3.0.CO;2-I

42. Troschke, E.; Grätz, S.; Lübken, T.; Borchardt, L. Angew. Chem., Int. Ed. 2017, 56, 6859-6863. doi:10.1002/anie.201702303

43. Grätz, S.; Wolfrum, B.; Borchardt, L. Green Chem. 2017, in press. doi:10.1039/C7GC00693D

44. Ribeiro, P. C.; de Melo da Costa, A. C. F.; Kiminami, R. H. G. A.; Sasaki, J. M.; Lira, H. L. Mater. Res. (Sao Carlos, Braz.) 2013, 16, 468-472. doi:10.1590/S1516-14392012005000176

45. Pechini, M. P. Method of Preparing Lead and Alkaline Earth Titanates and Niobates and Coating Method Using the Same To Form a Capacitor. U.S. Patent US3330697 A, July 11, 1967.

46. Strubel, P.; Althues, H.; Kaskel, S. Carbon 2016, 107, 705-710. doi:10.1016/j.carbon.2016.06.075

47. Sevilla, M.; Fuertes, A. B. ACS Nano 2014, 8, 5069-5078. doi: $10.1021 / \mathrm{nn} 501124 \mathrm{~h}$

48. Ferrero, G. A.; Sevilla, M.; Fuertes, A. B. Carbon 2015, 88, 239-251. doi:10.1016/j.carbon.2015.03.014

49. Tao, X.; Chen, X.; Xia, Y.; Huang, H.; Gan, Y.; Wu, R.; Chen, F.; Zhang, W. J. Mater. Chem. A 2013, 1, 3295-3303. doi:10.1039/c2ta01213h

50. Vasconcelos, D. C. L.; Costa, V. C.; Nunes, E. H. M.; Sabioni, A. C. S.; Gasparon, M.; Vasconcelos, W. L. Mater. Sci. Appl. 2011, 2, 1375-1382. doi:10.4236/msa.2011.210186

51. Hočevar, M.; Berginc, M.; Topič, M.; Krašovec, U. O. J. Sol-Gel Sci. Technol. 2010, 53, 647-654. doi:10.1007/s10971-009-2144-6

52. Oschatz, M.; Boukhalfa, S.; Nickel, W.; Lee, J. T.; Klosz, S.; Borchardt, L.; Eychmüller, A.; Yushin, G.; Kaskel, S. J. Mater. Chem. A 2014, 2, 5131-5139. doi:10.1039/c3ta14815g

53. Nelles, J. Preparation of Titanium Alcoholates and Phenolates. U.S. Patent US2187821 A, Jan 23, 1940.

54. Hernández, J. G.; Friščić, T. Tetrahedron Lett. 2015, 56, 4253-4265. doi:10.1016/j.tetlet.2015.03.135

55. Kim, K.; Choi, M.; Ryoo, R. Carbon 2013, 60, 175-185. doi:10.1016/j.carbon.2013.04.011

56. Frackowiak, E. Phys. Chem. Chem. Phys. 2007, 9, 1774-1785. doi:10.1039/b618139m 
57. Fuertes, A. B.; Lota, G.; Centeno, T. A.; Frackowiak, E. Electrochim. Acta 2005, 50, 2799-2805.

doi:10.1016/j.electacta.2004.11.027

58. Weingarth, D.; Foelske-Schmitz, A.; Wokaun, A.; Kötz, R.

Electrochem. Commun. 2012, 18, 116-118.

doi:10.1016/j.elecom.2012.02.040

59. Ruch, P. W.; Cericola, D.; Hahn, M.; Kötz, R.; Wokaun, A

J. Electroanal. Chem. 2009, 636, 128-131.

doi:10.1016/j.jelechem.2009.09.007

\section{License and Terms}

This is an Open Access article under the terms of the Creative Commons Attribution License

(http://creativecommons.org/licenses/by/4.0), which permits unrestricted use, distribution, and reproduction in any medium, provided the original work is properly cited.

The license is subject to the Beilstein Journal of Organic Chemistry terms and conditions:

(http://www.beilstein-journals.org/bjoc)

The definitive version of this article is the electronic one which can be found at: $\underline{\text { doi:10.3762/bjoc. } 13.130}$ 